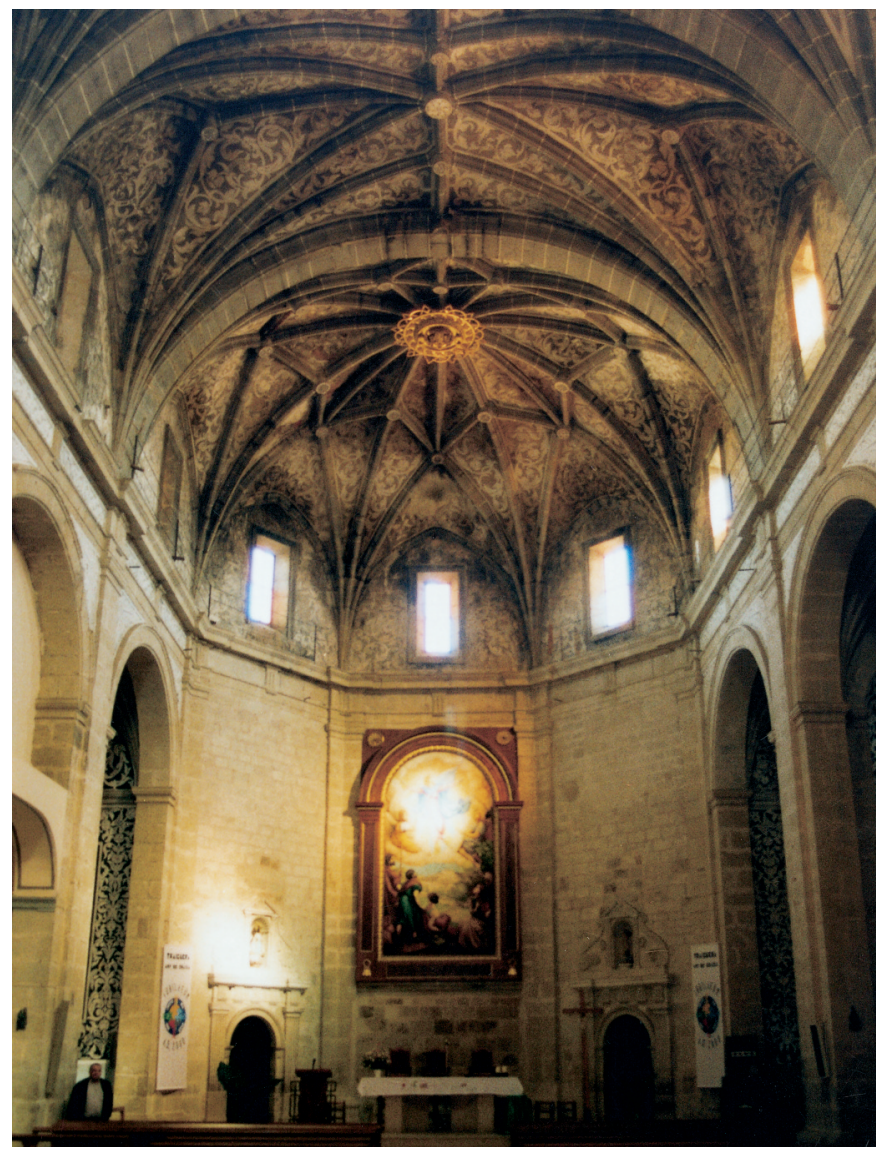

Interior de la iglesia antes de la restauración

\title{
Consolidación y restauración de revocos esgrafiados en la íglesia parroquial de Nuestra Señora de la Asunción de Traiguera
}

Milos Gavenda*, Jiri Hosek ${ }^{* *}$ y Jan Kopeck ${ }^{* * *}$

La intervención del artículo anterior se realizó juntamente con la consolidación y restauración del magnífico manto de esgrafiados que decora las bóvedas del templo que se presenta a continuación. Esta actuación constituye un caso ejemplar de estudio y análisis material de revocos esgrafiados previo a su rescate incluso en aquellos casos donde parecía imposible su recuperación, dado el estado de deterioro y las dificultades presentes. Representa además una aportación al conocimiento de la tradición de los revocos esgrafiados en el Levante español, tanto en su materialidad como en su iconografía.
Consolidation \& Restoration of the Sgraffito Finish of the Parish Church of Traiguera. The intervention mentioned in the article above was carried out at the same time as the consolidation and restoration of the magnificent sgraffito work decorating the vaults of the church described below. This operation constitutes an exemplary case for the study and material analysis of sgraffito plaster before restoration even in cases where the advanced state of deterioration and the many difficulties that arose made it seem impossible to rescue it. Furthermore, it increases our knowledge of both the materiality and the iconography of sgraffito plaster tradition in the Spanish Levant.materiality and the iconography of sgraffito plaster tradition in the Spanish Levant.

*Milos Gavenda es restaurador. **Jiri Hosek es ingeniero edil y profesor de ingeniería en la Facultad de Ingeniería Edil de Praga. ***Jan Kopeck es geólogo Agradecemos a Vera Hofbauerová su generosa traducción de este artículo 


\section{Consolidación y restauración de revocos esgrafiados}

Los revocos esgrafiados con ornamentación vegetal del interior de la iglesia en Traiguera, realizados sobre un revoco más antiguo, se pueden considerar como una obra única en su género que sobrepasa las fronteras de la región; sin exagerar se puede afirmar que se trata de una obra excepcional también en un contexto europeo. La excepción reside no sólo en la extensión de los esgrafiados -en la época de su realización cubrieron todas las paredes y bóvedas de la iglesia- y su valor artístico e histórico, sino también en la originalidad de la técnica utilizada. Mientras que para los esgrafiados en el resto de Europa, tradicionalmente se empleaban tecnologías a base de cal, en Traiguera, como demuestran los análisis efectuados, se usó el yeso de aglomerante, incluyendo la capa de intonaco bianco. Hay que remarcar que, igualmente, la técnica utilizada en el corte de las formas vegetales es muy peculiar ya que consigue dar la impresión de una decoración luminosa en alabastro. La obra posee una calidad artística y artesanal excelente, que refleja el alto nivel del saber profesional de los artesanos del siglo XVII de la región.

\section{Estudio y clasificación de daños}

Antes de comenzar los trabajos de restauración, se realizó un extenso sondeo y análisis dirigido a determinar el alcance, carácter y las causas de los daños. Estos trabajos se organizaron con suficiente antelación a la intervención para poder así elegir las técnicas de limpieza y conservación más adecuadas. Los daños se pueden agrupar en cuatro categorías según su apariencia y causa:

a) Desintegración material del revoco base, con la consecuente separación del esgrafiado. La causa fue la penetración persistente de agua a través de fisuras en la estructura base. La degradación material se vio puntualmente acelerada por la indeseada presencia de sales agresivas.

b) Separación de las dos capas de esgrafiados del revoco base, causada por falta de adherencia y por daños estructurales en los muros y bóvedas.

c) Separación de la capa superior del esgrafiado, unida a su lavado y posterior desaparición. Este daño se centra sobre todo en los enjarjes de nervios y senos de las bóvedas: son las zonas donde más se acusa la acumulación de agua de lluvia por la falta de mortero de juntas en la mampostería de muros.

d) Cambio de colorido-oscurecimiento- de la capa superior causada por una mezcla de sedimentos superficiales - polvo, hollín, residuos de humo- con el intonaco bianco y con el agua de lluvia que penetra por los muros con un deficiente rejuntado.

Una vez la influencia de los agentes exteriores en los daños fue palmaria, se realizó una exhaustiva documentación fotográfica de todos los paramentos afectados. Un problema considerable para la adecuada elección de técnicas de consolidación fue la baja capacidad de adherencia entre la capa inferior de esgrafiados y el revoco base. Es muy probable que este problema existiera ya en origen. Así lo atestiguaron las incisiones en el revoco, pero su eficacia, como se observó en el estudio, era solo parcial.
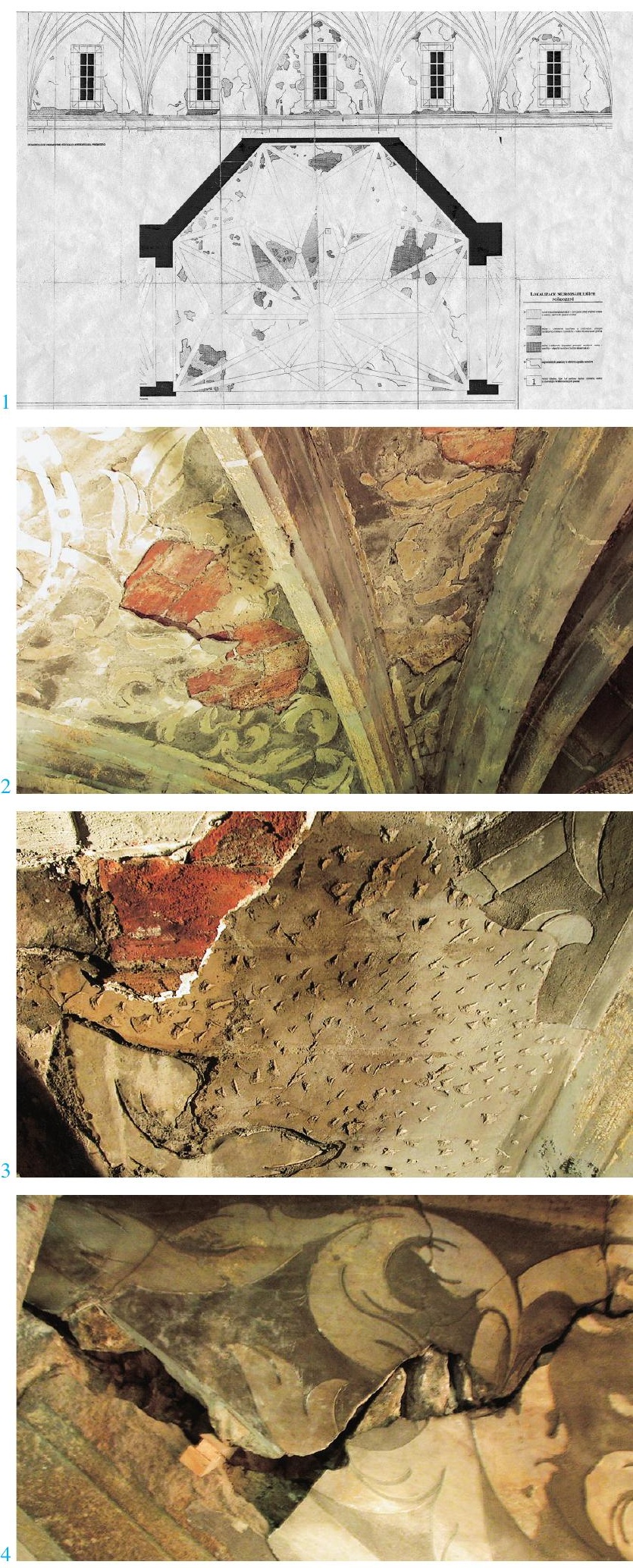

1. Característica y alcance de los daños más significativos en el presbiterio

2. Ejemplo de conjunto de daños y su alcance

3. Desprendimiento de esgrafiados causado por humedades. Se observa también el revoco base y la bóveda tabicada 4. Grietas y desprendimientos del revestimiento causados por movimientos estructurales de la bóveda y los nervios 
Tabla I. Análisis químico de la capa de base del esgrafiado

\begin{tabular}{|l|c|}
\hline Determinación & \% de peso \\
\hline & \\
\hline & 13,00 \\
\hline Pérdida por recocido & 49,96 \\
\hline Residuo insoluble & 0,75 \\
\hline Dióxido de silicio $\mathrm{SiO}_{2}$ & 0,48 \\
\hline Óxido férrico $\mathrm{Fe}_{2} \mathrm{O}_{3}$ & 0,93 \\
\hline Óxido de aluminio $\mathrm{Al}_{2} \mathrm{O}_{3}$ & 21,82 \\
\hline Óxido de cal $\mathrm{CaO}$ & 1,05 \\
\hline Óxido de magnesio $\mathrm{MgO}$ & 11,96 \\
\hline Trióxido de azufre $\mathrm{SO}_{3}$ & \\
\hline
\end{tabular}

Tabla II. Análisis químico de la capa inferior del esgrafiado

\begin{tabular}{|l|c|}
\hline Determinación & \% de peso \\
\hline & \\
\hline & 14,31 \\
\hline Pérdida por recocido & 42,98 \\
\hline Residuo insoluble & 0,35 \\
\hline Dióxido de silicio $\mathrm{SiO}_{2}$ & 0,20 \\
\hline Óxido férrico $\mathrm{Fe}_{2} \mathrm{O}_{3}$ & 0,88 \\
\hline Óxido de aluminio $\mathrm{Al}_{2} \mathrm{O}_{3}$ & 22,33 \\
\hline Óxido de cal $\mathrm{CaO}$ & 0,62 \\
\hline Óxido de magnesio $\mathrm{MgO}$ & 18,30 \\
\hline Trióxido de azufre $\mathrm{SO}_{3}$ & \\
\hline
\end{tabular}

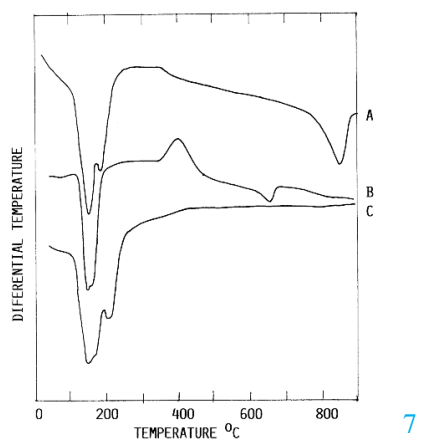

5. Análisis químico del revoco base

6. Análisis químico de la capa inferior gris del esgrafiado (intonaco nero)

7. Curvas DTA de las muestras de las tres capas de revoco 8. Análisis EDX. Testimonio de presencia de un material plastificante en la capa superior - intonaco bianco -. En el microanálisis de elementos EDX se muestra un $95 \%$ de carbono y oxígeno en la composición de la masa. Otros componentes tienen una mínima representación. El hidrógeno no se puede detectar con el microanálisis EDX.

9. Análisis EDX de partículas de una astilla de madera que demuestra la estructura molecular de masa lígnea

10. Análisis EDX. Composición química de anhídrido carbónico $\mathrm{CaSO}_{4}$

11. Análisis EDX. Composición química de la capa superior intonaco bianco - formada casi exclusivamente por anhídrido carbónico $\mathrm{CaSO}_{4}$

12. Observación con ESEM. Estructura de la capa superior - intonaco bianco - unida con la capa inferior - intonaco nero - de esgrafiado que, a su vez, contiene partículas de carbón vegetal

13. Observación con ESEM. Detalle de estrutura de revoco con trozo de carbón vegetal. En el carbón es bien reconocible la estructura molecular de masa lígnea

\section{Análisis de laboratorio}

Durante el estudio previo se tomaron muestras representativas de las distintas superficies dañadas, que analizadas en laboratorio dieron respuestas a algunas cuestiones necesarias de conocer antes de iniciar los trabajos. En primer lugar se debía averiguar la composición material del revoco base y de ambas capas de los esgrafiados. Por este motivo se realizó un análisis químico, cuyo resultado se expone en las tablas que se acompañan (figs. 6, 7)

Revoco base. Los resultados obtenidos tras el análisis químico demuestran que en el revoco base se utilizó como conglomerante el yeso. Por cálculo se determinó una aproximada proporción volumétrica de la mezcla de yeso en forma de anhídrido $\mathrm{CaSO} 4$, cal aérea $\mathrm{CaO}$ y aglomerante: 1 : $0,6: 2,5$

El análisis químico no logró discernir claramente la clase de aglomerado utilizado. Un polvito muy fino creaba un resto insoluble que recordaba por su consistencia a la caolinita: esta posibilidad quedó subrayaba también por la presencia de óxidos de $\mathrm{Si}, \mathrm{Al}$ y Fe. Para aclarar el problema se emplearon, como métodos complementarios, el análisis térmico, un microscopio electrónico de barrido (ESEM) y microanálisis (EDX). Por la síntesis de los datos obtenidos con los tres métodos y tras su evaluación se llegó a la conclusión que como aglomerado se habían utilizado materiales arcillosos. Se sabe que los morteros que contienen arcillas se caracterizan por variaciones de su volumen durante el fraguado: con mucha probabilidad fue el "encogido" de la capa inferior del esgrafiado una de las causas de su separación del revoco base.

Intonaco nero. La capa inferior gris del esgrafiado -intonaco nero- se preparó con la mezcla de anhídrido $\mathrm{CaSO} 4$, cal aérea $\mathrm{CaO}$ (plastificante) y materiales arcillosos en proporción de $1: 0,3: 1,4$. Como colorante se utilizaron partículas de arbustos carbonizados. Las imágenes obtenidas por el microscopio electrónico así lo demuestran e incluso facilitan el reconocimiento de su estructura molecular.

Intonaco bianco. La capa superior blanca -intonaco bianco- se aplicó sobre la capa inferior cuando ésta todavía estaba sin endurecer; así se consiguió una perfecta unión por compenetración de las dos capas. Esta compenetración se observa en las imágenes del microscopio electrónico. El anhídrido obtenido por la carbonización del alabastro era la base de esta pasta de yeso, extendida en un grueso de aprox. 1-2 mm. El microanálisis muestra que la mezcla contenía un añadido, probablemente de origen orgánico (peak $211^{\circ} \mathrm{C}$ ) que actuaba como plastificante, retardaba el fraguado y elevaba la consistencia de intonaco bianco una vez fraguado. De los análisis realizados, no obstante, no es posible averiguar más detalles. 


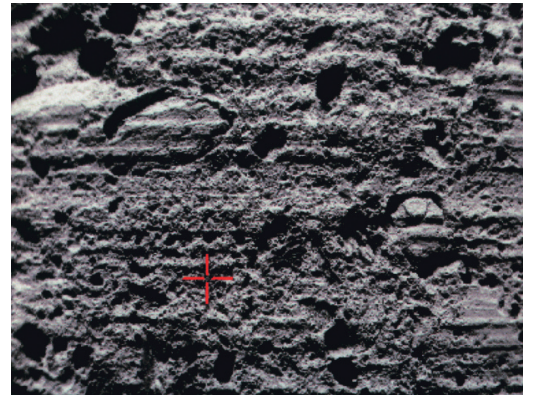

Element
CK
OK
NaK
MgK
AlK
SiK
SK
CIK
KK
CaK

Wt $\%$

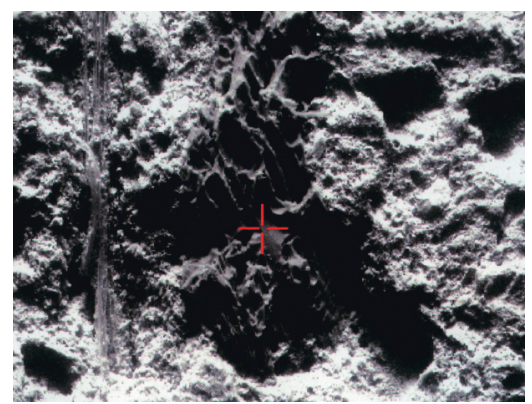

Element $\quad$ Wt $\% \quad$ At $\%$

$\mathrm{CK}$
$\mathrm{OK}$
$\mathrm{NaK}$
$\mathrm{SK}$
$\mathrm{CIK}$
$\mathrm{KK}$
$\mathrm{CaK}$

74,29

19,66

0,86

0,78

0,74

2,39

Element Wt $\% \quad$ At $\%$

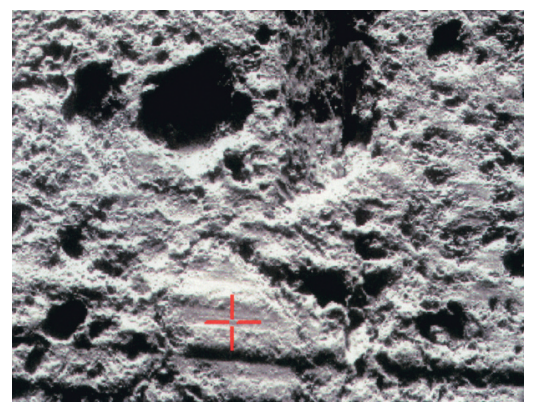

$\begin{array}{lll}\text { OK } & 42,47 & 65,52 \\ \text { SK } & 25,02 & 18,38 \\ \text { CaK } & 32,51 & 19,10\end{array}$

Element $\quad$ Wt $\% \quad$ At $\%$

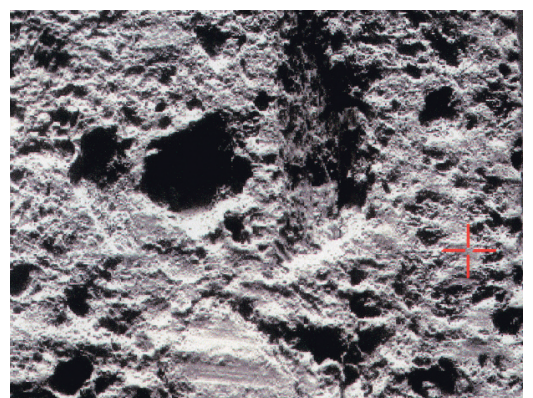

$\begin{array}{lll}\text { OK } & 47,14 & 66,77 \\ \text { SK } & 23,67 & 16,73 \\ \text { CaK } & 29,18 & 16,50\end{array}$
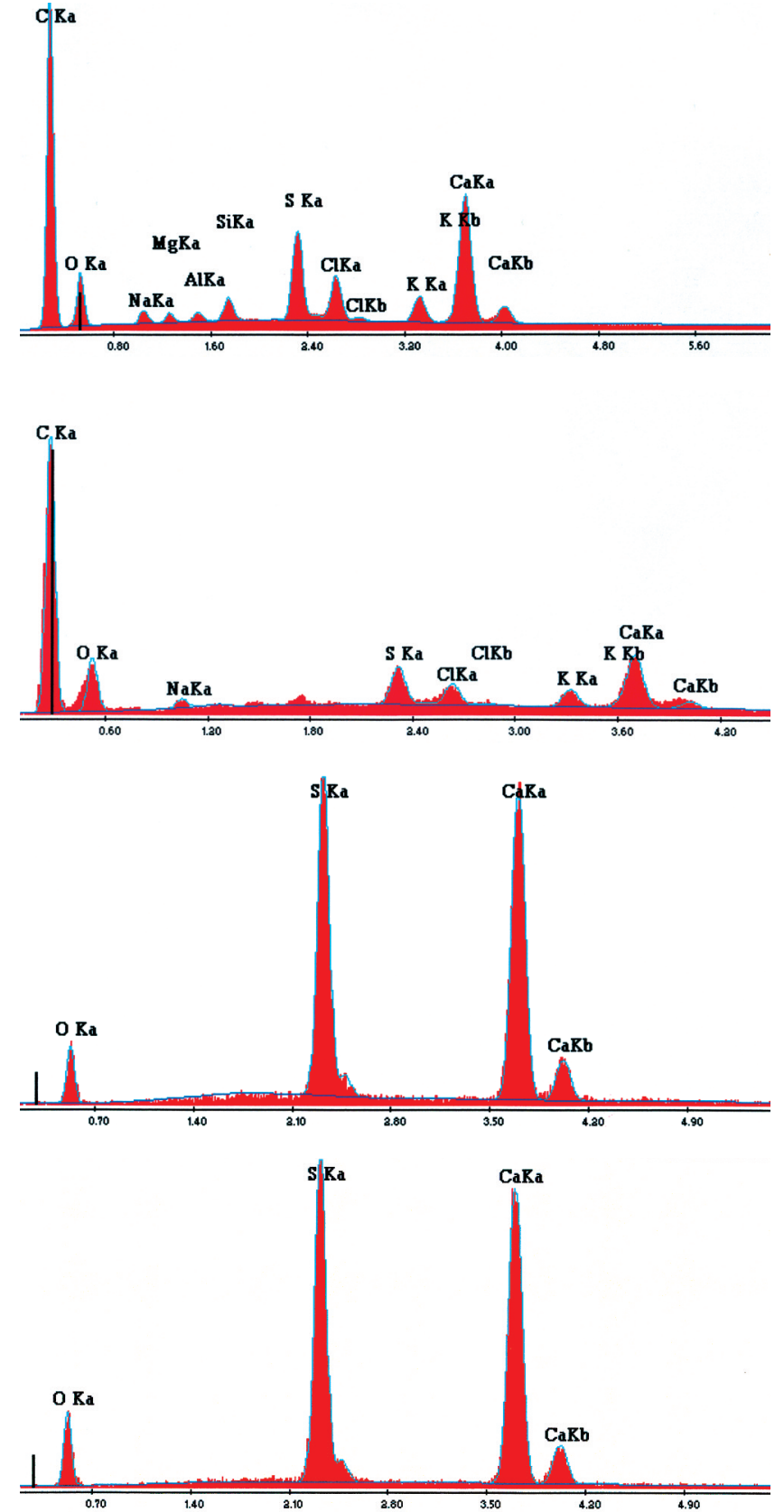
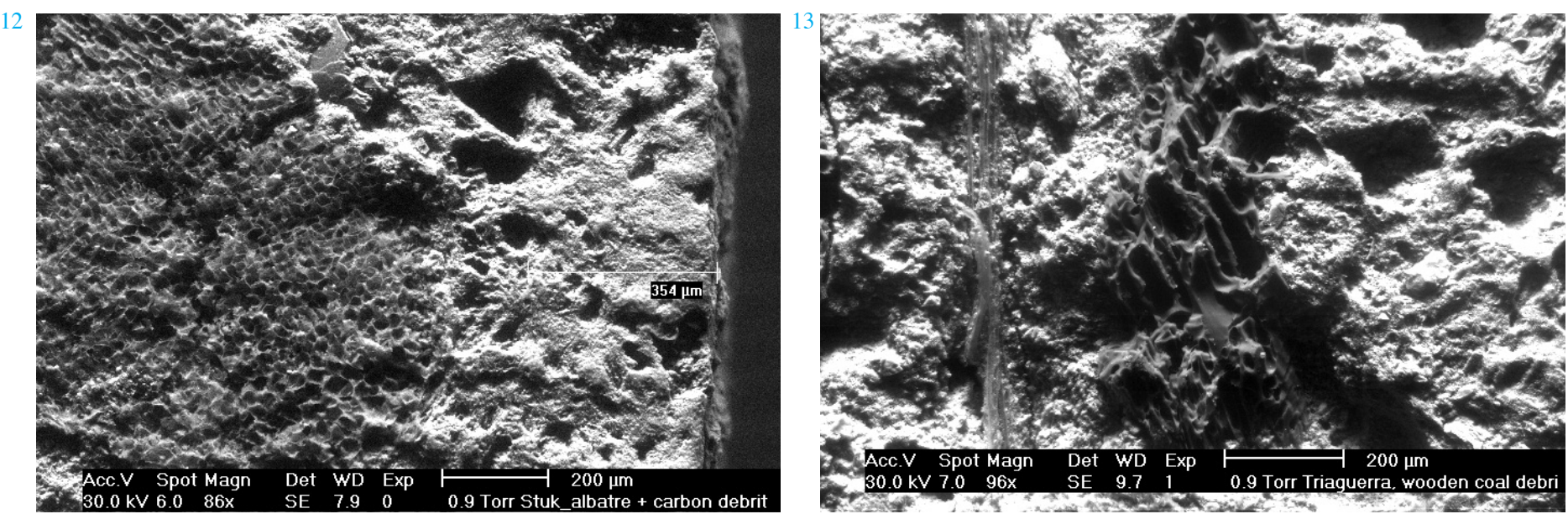

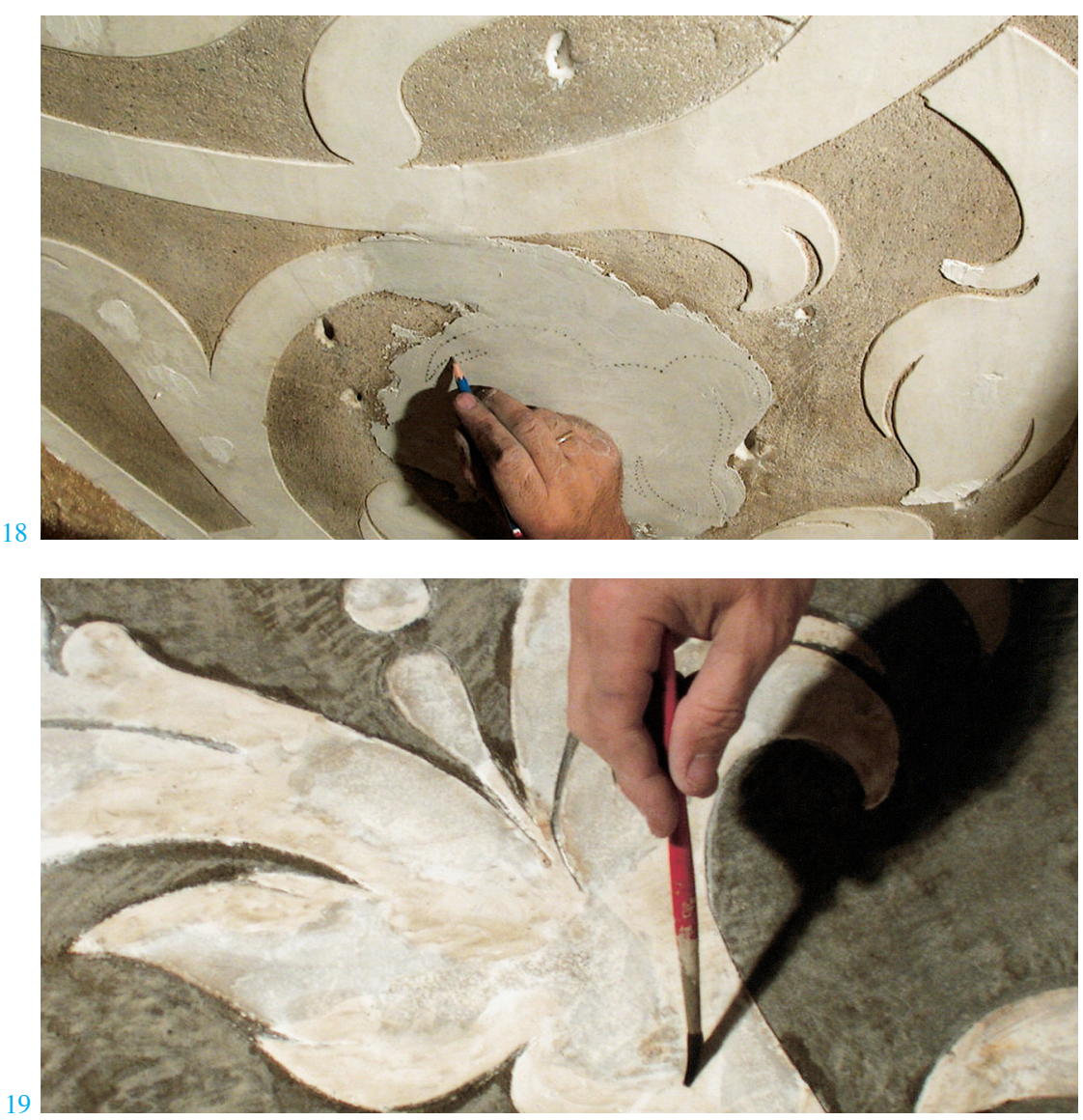

capa, superficialmente bien alisada y compactada con una llana, que lleva una decoración de sillares fingidos, dibujados con pintura de cal sobre una cuadricula marcada previamente con un objeto punzante. La finalidad de la decoración era el ennoblecimiento del paramento construido con ladrillos. Se puede suponer que en la primera etapa constructiva de la iglesia, cuando existía sólo el presbiterio, todo el interior estaba decorado con esta clase de revoco.

Muy interesante es la talla superficial de los nervios pétreos de la bóveda del presbiterio, distinta al resto de la iglesia, y característica igualmente de la Edad Media. Es decir, que las aristas están trabajadas con una herramienta especial hasta dejarlas lisas, a diferencia de las otras superficies profundas que son rugosas. La finalidad de este tipo de labra es lograr un mayor efecto óptico de una acentuada profundidad de la perfilación.

Durante varios sondeos orientativos y puntuales en distintos lugares de la iglesia se descubrió otro tipo de dibujo de decoración ornamental antigua, claramente diferenciada de los esgrafiados actualmente restaurados. Sería interesante ampliar este conocimiento, estudiando zonas más extensas tanto de los paramentos verticales como de las bóvedas.

Para finalizar cabe añadir que una sensible elección de las distintas técnicas de restauración, elegidas individualmente para cada zona dañada, atendiendo siempre el grado y la causa de su degradación, facilitó la recuperación de esta bella y exclusiva decoración del edificio sacro de Traiguera.
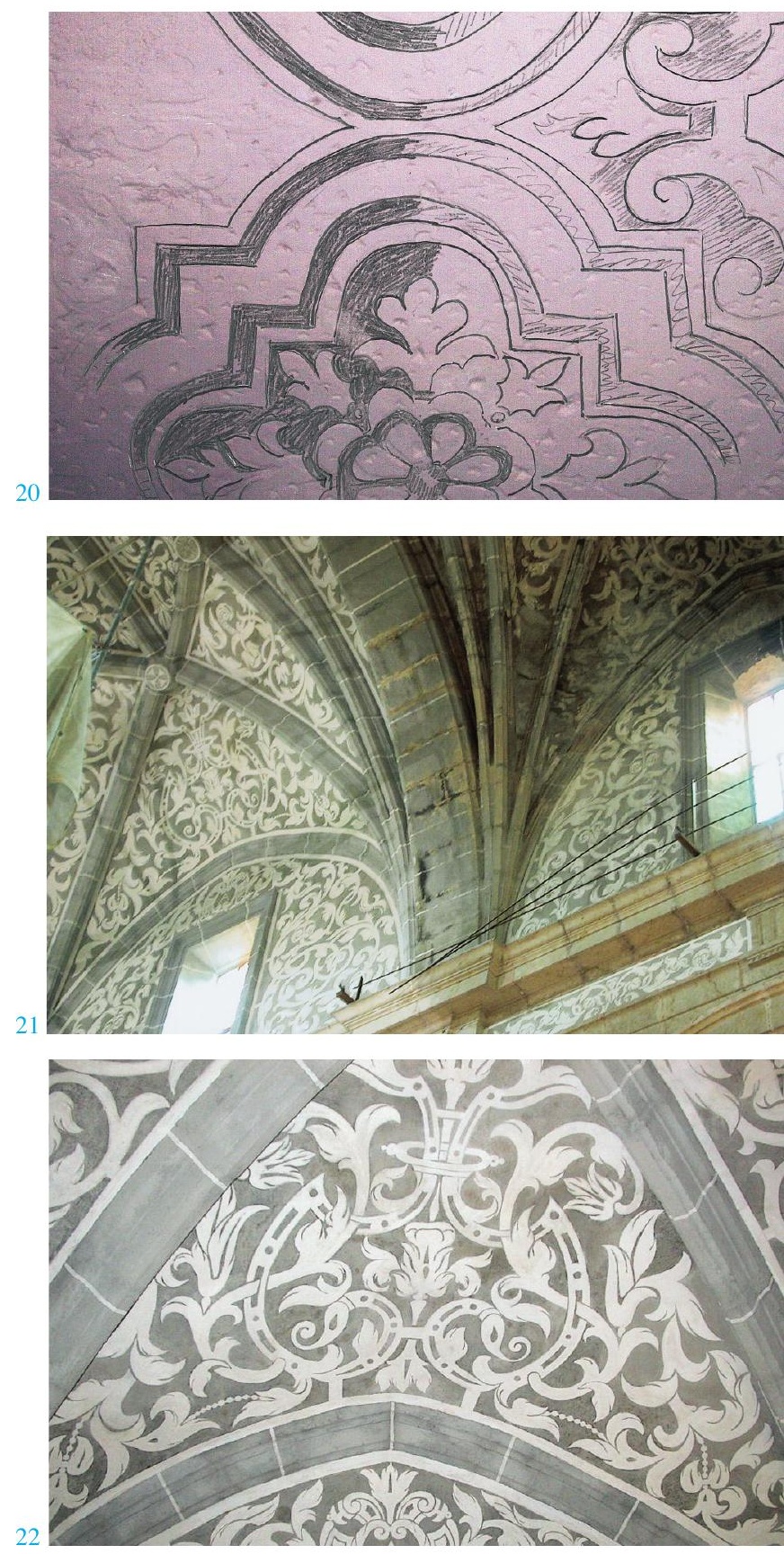

14. Fijación y consolidación previa de las partes desprendidas, con peligro de caída

15. Red de microtaladros necesaria para la consolidación volumétrica realizada con inyección de emulsión aguosa de cal, etc. en un parte original, completamente desprendida de la base

16. Superficie con apósito para la extracción de sales dañinas

17. Una superficie con esgrafiados originales para su transferencia temporal. Este proceso se realizaba en zonas de un total desprendimiento y con necesidad de consolidación de la bóveda tabicada

18. Restitución de una superficie de esgrafiados

19. Entonación cromática de las partes restituidas

20. Dibujo de otro tipo de revoco decorativo encontrado en un sondeo de un paramento de la iglesia

21. Fotografía comparativa con superficies restauradas y sin restaurar

22. Revocos esgrafiados restaurados 